\title{
Cerebral Visual Impairment on the Web: An Exploration of an Educational Web Resource as a Bridge to Public Understanding
}

OPEN ACCESS

Edited by:

Vinita Agarwal,

Salisbury University, United States

Reviewed by:

Liz Sillence, Northumbria University,

United Kingdom

Maria Beatriz Torres,

Mercyhurst University, United States

*Correspondence:

John Ravenscroft

john.ravenscroft@ed.ac.uk

Specialty section:

This article was submitted to

Health Communication,

a section of the journal

Frontiers in Communication

Received: 23 June 2021 Accepted: 26 August 2021 Published: 15 September 2021

Citation:

Ravenscroft J, St Clair Tracy $\mathrm{H}$ and

Blaikie A (2021) Cerebral Visual Impairment on the Web: An Exploration of an Educational Web Resource as a

Bridge to Public Understanding.

Front. Commun. 6:727230.

doi: $10.3389 /$ fcomm.2021.727230

\author{
John Ravenscroft ${ }^{1 \star}$, Helen St Clair Tracy $^{2}$ and Andrew Blaikie ${ }^{2}$ \\ ${ }^{1}$ The Scottish Sensory Centre, Moray House School of Education and Sport, University of Edinburgh, Edinburgh, \\ United Kingdom, ${ }^{2}$ Infection and Global Health Division, School of Medicine, University of St Andrews, St Andrews, \\ United Kingdom
}

Cerebral Visual Impairment (CVI) is the most common form of childhood visual impairment. Yet it remains the least well understood by parents and professionals alike. There is an urgent need to provide a bridge between academic knowledge concerning $\mathrm{CVI}$, and to give a practical understanding of the condition to those affected, parents, carers, and professionals alike so that a common language can be shared between patients, their carers and professionals. The wide ranging manifestations of $\mathrm{CVI}$, and the lack of accessible well recognised terms to describe it, render it difficult to understand how someone with their own unique form of CVI actually "sees". However, with graded progressive explanation, knowledge can be gained, leading to an understanding of the visual effects of $\mathrm{CVI}$ from the perspective of those affected. The current position of limited understanding of the condition presents a major challenge for health and education professionals: How does one bring about the requisite CVI literacy, to render the subject accessible to families, affected children and adults, and the public?

One way of doing this is by means of a plain language, multi-media resource, hosted on a publicly available website, driven by a partnership of adults with CVI, parents of children with the condition and experienced professionals from around the world, including those from the vision sciences and education. Within this context, we have explored the website resource of the not-for-profit organisation CVI Scotland (https://cviscotland.org/). This comprises a growing body of CVI knowledge created for teaching, sharing, learning and developing knowledge and understanding. By analysing anonymised data concerning the activity of 80,000 users from 170 countries, we have examined where the users who are accessing the website come from, what users are seeking in terms of information, how they have accessed the website, and what devices they use. The results are interpreted though frequency analysis and linear regression. Based on this analysis several recommendations are made in terms of disseminating information about CVI to members of the public as well as developments to enhance the website itself. To our knowledge this is the first study to examine the use of a website dedicated to CVI using Google analytics.

Keywords: cerebral visual impairment, CVI literacy, public understanding, google analytics, web analysis, common language 


\section{INTRODUCTION}

Cerebral visual impairment (CVI) is recognised to be an umbrella term embracing a wide variety of brain-related visual and perceptual difficulties affecting the way a person sees, experiences and understands their world (Dutton, 2021). The diversity of expression has caused difficulty reaching an agreed definition. The definition recently recommended by Sakki et al., is a "Verifiable visual dysfunction which cannot be attributed to disorders of the anterior visual pathways or any potentially cooccurring ocular impairment" (Sakki et al., 2018, p430). It is derived from a comprehensive literature review and merits consideration of acceptance. CVI has become the leading cause of visual impairment in children in high-income countries and has an increasing prevalence in low-income countries (Kong et al., 2012). Recent literature has shown that the numbers of children attending primary schools in the UK with at least one CVI related visual difficulty has been significantly underestimated (Williams et al., 2021). Similarly, Teoh et al. (2021), have identified that $48 \%$ of 784 children in the British Childhood Visual Impairment and Blindness Study 2 (BCVIS2) have disorders of the brain and their visual pathways. It is important to note that CVI should not be considered a childhood disorder only, CVI can be acquired at any age due for example to head injury, epilepsy, infection and progressive ageing conditions such as dementia (Soul and Matsuba, 2010).

CVI has been recognised as a medical condition, as early as the first world war when the ophthalmologist Gordon Holmes mapped out the visual pathways by means of studying the vision of soldiers with penetrating visual brain injuries Holmes (1918a), Holmes (1918b), Holmes (1918c), and Riddoch a neurologist first reported the phenomenon of patients who were "cortically blind' seeing moving targets (Riddoch, 1917). Riddoch observed that the soldiers he studied were aware of movement in visual field areas that did not see static targets as a result of injury to their occipital lobes (ibid). This is known as the Riddoch Phenomenon (Arcaro et al., 2019). It is most commonly seen in adults with acquired brain injury (Head et al., 1920). It is only relatively recently that the literature has become propagated with the term CVI (Sakki et al., 2018). This development has coincided with the growth of the internet and social media as an alternative information source for patients to come to understand their own health issues, offering the opportunity to further promote greater knowledge and wider interest in CVI.

Understanding CVI is an important concern for health communication as all diseases need a common language which is understood by all professionals and by all patients/carers. However, CVI which has been investigated since 1917 has been mainly in the realm of vision and brain scientists with its own nuanced vocabulary such as dorsal/ventral streams, simultanagnosia, and optic ataxia, and hence CVI explanations have not as yet gained the same traction as other diseases in getting a clear plain shared language across professional and patient domains. If poor understanding occurs, then advice may be misunderstood or mistaken meaning the patient may suffer. It is known that plain language is important in health care information (Warde et al., 2018; Wicklund and Ramos 2009). Therefore, any medium, such as a plain English website that aims to explain the complexities of CVI, becomes of use and interest to not only patients but also to the general medical profession.

The use of the internet to seek medical information has become widespread among those who have access to it. Patients, families and carers are increasingly using the internet to search for health information and to gain greater understanding of their medical diagnoses. The internet as a source of information has the potential to not only inform, but also to enhance and to empower patient understanding and agency (Brewer et al., 2005).

Health seeking information, however, is not uniformly distributed throughout the population. The causes of this digital disparity in health seeking information has been identified as having greater access to internet enabled devices such as mobile phones or computers/laptops, being female and having a graduate degree (Lee et al., 2021). Jacobs, Amuta and Jeon (2017) also suggest health information seeking users are younger, more educated and from higher social economic status. This digital divide exists also in trusting the information seekers have found. A study by Fareed et al. (2021) found that black respondents, relative to white, had greater odds of having high confidence, and Hispanic respondents, relative to white, had lower odds of having high confidence in their ability to attain health information and to trust that information from a wide variety of sources such as newspapers and magazines, radio, the internet, television, government, charitable organizations, and religious organizations.

Pang et al. (2016) have identified four different search behaviours. The first of these is the "Quick Fact Seeking Strategy," which sees the internet user stopping their search quickly once they have found a brief answer to their health query. The next category identified, is the "All-roundSkimming Searcher," who peruses specific websites and information in a quick manner, rapidly clicking onto the next piece of information. The third category of internet health search user, is the one who becomes a "Focused Reader," where time is spent on a particular page or website while the information contained is accessed. The final category comprises the "Knowledge and Digger Individual" who carries out comprehensive research on particular issues and will visit varied websites in-depth, to find out as much information as possible.

Several studies have investigated why people search for and consume health information. A well-known 2013 study conducted by Fox and Duggan on behalf of the Pew Internet Project found that $59 \%$ of adults living in the United States have searched online for information concerning a range of health issues, the most popular being specific diseases and treatments. One-in-four (26\%) adult internet users say they have read or watched on-line videos from people sharing their experiences, about health or medical issues in the previous 12 months. And $16 \%$ of adult internet users in the U.S. have gone online in the past 12 months to find others who share the same health concerns as themselves (Fox and Duggan, 2013). Seeking social support from other patients with similar diagnoses is an important additional 
reason why people use the internet as a source of health information. Such social support has been found to aid empowerment, enabling exchange of information, and enhancing understanding (Krann et al., 2008).

The changing ways patients access health information have caused a shift from informed patient care to patient informed care, (Gardiner, 2008). However, this shift has required patients to accept the internet as a source of medical health information where they feel they have not been given adequate health information from their medical practitioner (Martini and Bragazzi, 2021). It seems from the literature, that whilst there is increasing use of the internet as a means of understanding diagnoses and health related information, this approach fortunately does not lead to patients feeling their internet based activates have an adverse effect on their relationship with their own health professional, (Russ, et al., 2011; AlGhamdi and Moussa, 2012). However concern has been expressed that patients may not have the necessary ability to discriminate correct and reliable information, from that which is incorrect and unreliable (Ahluwalia et al., 2010). In a systematic review of internet health information and the patient physician relationship, Tan and Goonawardene (2017), did find that internet health information seeking can improve the patientphysician relationship. This however depends upon whether the patient discusses the information with the physician, and upon the quality of their prior relationship.

Having a child with CVI is akin to any other complex health condition, in that it can prove an extremely stressful and emotional time for parents (Rafferty and Sullivan, 2017). Grief, trauma and significant levels of stress have all been reported as parental issues within the first year of raising a child with disabilities (Young et al., 2020). One way of supporting parents through this difficult time has been to empower them with understandable information, with signposting to organisations and charities that can help and support families with children who have CVI (McDowell, 2020). However, the literature shows that this may not be happening due to a lack of understanding of CVI within the health practitioner community itself (Jackel et al., 2010; Martin et al., 2016; 2019; Gorrie et al., 2019). As a consequence parents of children with CVI will therefore often turn to the internet to seek additional information about their child's diagnosis and needs, in order to supplement limited explanations provided at the time of diagnosis.

In a recent paper McDowell, (2020) highlighted that at the time of diagnosis, only 49 of the 76 parents she investigated, received information about CVI through direct discussion with the professional, and fewer did so through books and leaflets. Interestingly, websites signposted to parents by professionals were identified as the most used source of information. However, in the same study it was reported that the parents who were identified as "least informed", (those parents who did not received any information) used other parents as their most common resource for additional information (McDowell, 2020). By contrast, the parents who were identified as "informed", were found to prefer professionals as a source of information over other parents. Clearly the work of McDowell, highlights the need to go beyond simply providing relevant, correct and up-to-date information about CVI; the information needs to be accessible and comprehensible to parents and carers of people with CVI in order to narrow the communication gap between them and the professionals they encounter (Hodge and Runswick-Cole 2008; Ahluwalia et al., 2010; Alghamdi and Moussa, 2012; McDowell, 2021).

One way to establish combined lay person and professional CVI literacy that is common to both, is through a plain language multi-media resource, hosted on a publicly available website. As such we have examined how the not-for-profit organisation CVI Scotland website (https://cviscotland.org/) launched in 2017, has sought to address some of the concerns identified in McDowell's paper. The website focuses on a medical issue that is not part of mainstream concerns; but highlights why it is important to focus on CVI. Through this focus this site has become an internationally accessed learning resource with information being sought by over 80,000 users from 170 countries, using it as a tool to enhance their own personal and professional CVI literacy and understanding.

As such the aim of this research is therefore to;

- Determine where the users accessing the website come from, and how they access the website.

- Understand the users interaction through the website.

- Identify any improvements that can be made to the website as a result of this analysis.

Our specific research question is through the analysis of google analytics what can we learn about the user interaction of a single medical condition website?

\section{METHOD}

In 2016 the charity "CVI Scotland" commissioned a bespoke website platform to promote understanding of CVI and its impact upon learning, behaviour, social development and independence across children and adults of all ages and abilities. The design and layout of the site recognized that the website would need to grow in different directions to encompass the wide range of visual disorders that come under the umbrella term of CVI. Initially CVI Scotland was developed with parents and carers primarily in mind, but the developers quickly realised from feedback that it was being used by a wide range of people that did include parents and carers but also children as well as the range of professional groups managing CVI. The website content was not initially aimed at informing professionals, but rather a broad source of information about CVI that focussed on establishing a common language, which could be used by anyone (professionals and parent alike) in order to understand the complexities of CVI.

The site was structured from the outset to comprise three blocks of content, each containing multiple subsection documents that together address the question "What Is CVI?". These blocks comprise the reference section for the website, and allow short accessible pieces to be added in a modular fashion, with links to more in-depth related information if the reader 
wishes. The platform hosts first-hand accounts of the experience of living with CVI provided by affected adults with CVI, and parents of affected children. A community of contributors has grown, and through open dialogue, the contributing team has started to learn more about CVI from one another. Many common lived experiences were not to be found in the medical literature and so there was no descriptive nomenclature. To promote awareness of these findings more widely, the team allocated new names to these common experiences with salient explanations in the hope of establishing a common language to promote understanding. From the outset, the core team has been supported by many colleagues internationally. Considerable time has consequently been invested in consulting and collaborating, to ensure that all information shared on cviscotland.org is as accessible and understandable to as many communities as is practical, including those working in medical eye care, vision scientists, teachers, parents, carers of children with CVI, and those affected by the condition.

The website, like a text book, has an A-Z index, contents (site map) and a glossary, and being on-line has search boxes throughout, with links between pages. No products or services are promoted, to ensure that the resource is without cost, competition or conflict, and therefore unbiased, and is of use to as many relevant groups as possible.

We used Google Analytics (GA) for the purpose of this study as this importantly, provides time series data generating detailed statistics about website visits and has an easily accessible dashboard to display data.

GA was used to analyse user data from May 1st' 2017 to april 30th' 2021, a total of 1,460 days. Focusing on the 4 years of operation from inception was considered the most appropriate approach in order to capture the development and growth of web traffic from launch. The GA data do not contain any identifiable personal information and they are presented in the form of aggregate data, making it an accessible tool for use without ethical concerns (Kirk et al., 2012; Clark et al., 2014). However this aggregated data does not allow us to distinguish between different categories of user, such as patient/carer, medial professional, or other professionals, nor does this current data set distinguish between race, economic status and education thus limiting some of the potential analysis we can do.

GA is possible by virtue of inclusion of a block of JavaScript code in the CVI Scotland website. When users visit the website, the JavaScript code links to the JavaScript files, and performs the tracking operation needed for analysis. This operation allows collection of various forms of data related to user behaviour. The data studied by this project arise from applying a range of avenues of approach including the Uniform Resource Locator (URL) of the page the user is viewing, the language the user's device has been set to, the name of the browser, and the device used to access the site.

A "user" is one person on one device accessing the website, recorded using cookies. If the same person accesses the website on a different device, for example their laptop and mobile phone, then they will be recorded as two users. If two people access the website from the same device, for example a shared home computer, they will be recorded as one user. The results reported are for both new and returning users unless explicitly specified.

Information is summarized in a real-time interactive dashboard format which clearly identifies the volume and nature of external engagement with the website. (Crutzen et al., 2013). highlight that GA data needs to be interpreted by linking it to other data in order for us to understand more about the user. For this reason we have linked the GA data to different countries and their population as well as their economic world health classification. This highlights differences in use between these countries suggesting difference in awareness and knowledge of CVI. We have used frequency analysis and linear regression supported by a Pearson's correlation to identify specific answers to our research question.

\section{RESULTS}

\section{Demographic Overview}

Over the 4 year period, over 80,000 different users have visited the CVI Scotland website during 141,051 separate sessions, viewing 512,459 pages. 92.3 percent of users access the website in English, although it has also been translated into 172 different languages and dialects by means of Google Translate. Figure 1 shows the rate of growth over the 4 year period as awareness of the site has increased worldwide.

Table 1 shows the exact percentage increase year on year resulting in a 184.3 percent increase of users accessing the website from Year one to Year 4.

The scatterplot, Figure 2 omits five outliers, (day 157/334 users; day739/407 users; day 1,396/371 users; day 1,423/479 users; day $1,456 / 555$ users) due to the unusually high increase of users on those particular days compared to the mean user day rate of (80.94) and the median number of users (71), and shows the linear relationship between users and the number of days the website has been active. A simple linear regression was carried out to investigate the relationship and the results showed that there was a strong positive linear relationship between the two, which was confirmed with a Pearson's correlation coefficient of $0.560, p<$ 0.01 (two tailed). A simple linear regression showed a significant relationship between the number of users and the number of days the website has been active. $(p<0.05)$. The more days the website has been active, more users have visited the website. The $R^{2}$ value was 0.313 so $31.3 \%$ of the variation of users can be explained by the model containing only active days of the website.

People are accessing the website either through entering the website address directly into a web browser, or through a website search engine such as Google or Bing. Table 2 shows that in total, $19.3 \%$ of the website traffic came from social media and only $6.8 \%$ came from a link from another website, while $74 \%$ of all traffic came either directly (meaning the webpage address was used), or through organic search using a browser.

Through the use of analysing the GA data we are able to determine that $45.8 \%$ of users were female and $54.2 \%$ male although one has to be cautious about this result as GA records this data from the account details the device is set up in. For example, if the google account of a shared home computer is registered to a 
man, but is used by a woman, GA will record the user as male, so this result should be interpreted with this limitation.

This is also the case for determining the age of the user, again GA records this data from the recorded account holder. With this limitation the majority (60\%) of users who accessed the website were between 18 and 34 years of age (Table 3 ).

Users under 18 years of age are not part of the age demographic collected by GA.

The majority of users access the site via a desktop/laptop computer, rather than a mobile phone or tablet (Table 4) with this finding remaining consistent throughout the 4 year period.

\section{Global Reach}

It is clear from the location of users accessing the website that CVI Scotland has gained a global reach. Figure 3 clearly shows that a significant part of the world (coloured in red) has accessed the CVI Scotland website.

Table 5 highlights that New Zealand, the UK, Ireland and Australia are the countries where most users per million of the population are found. It shows that each of the top 10 countries is within the World Bank's definition of being a high income nation with predominantly high levels of English literacy. South Africa, and Malaysia are the first

TABLE 1 | Percentage increase of users to the CVI scotland website.

\begin{tabular}{lcc} 
Users year 1 & Users year 2 & \% Increase \\
\hline 11,391 & 16,464 & $44.5 \%$ \\
\hline Year 2 & Year 3 & \% Increase \\
\hline 16,464 & 21,595 & $31.2 \%$ \\
\hline Year 3 & Year 4 & \% Increase \\
\hline 21,595 & 32,381 & $49.9 \%$ \\
\hline Year 1 & Year 4 & \% Increase \\
\hline 11,391 & 32,381 & $184.3 \%$ \\
\hline
\end{tabular}

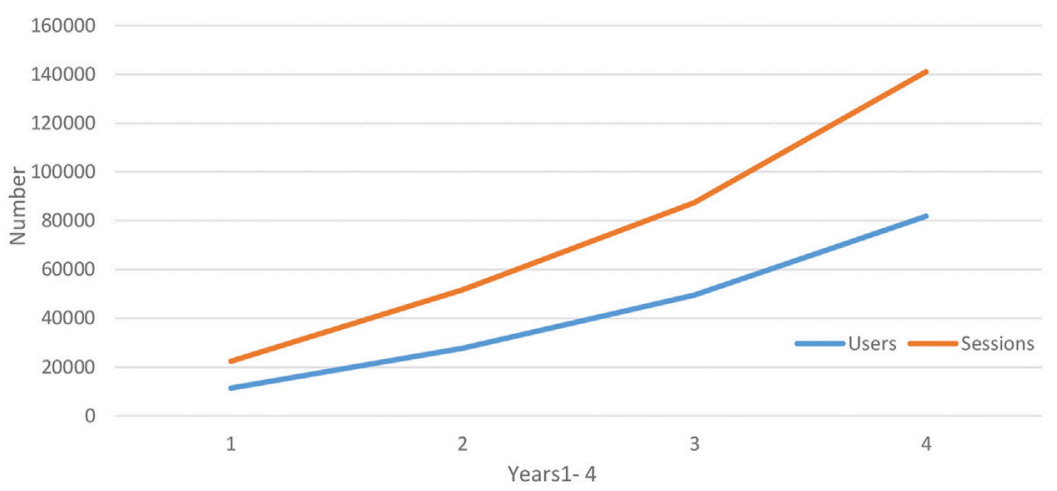

FIGURE 1 | Graph showing the cumulative increase of users and sessions to the CVI Scotland website over a 4 year period.

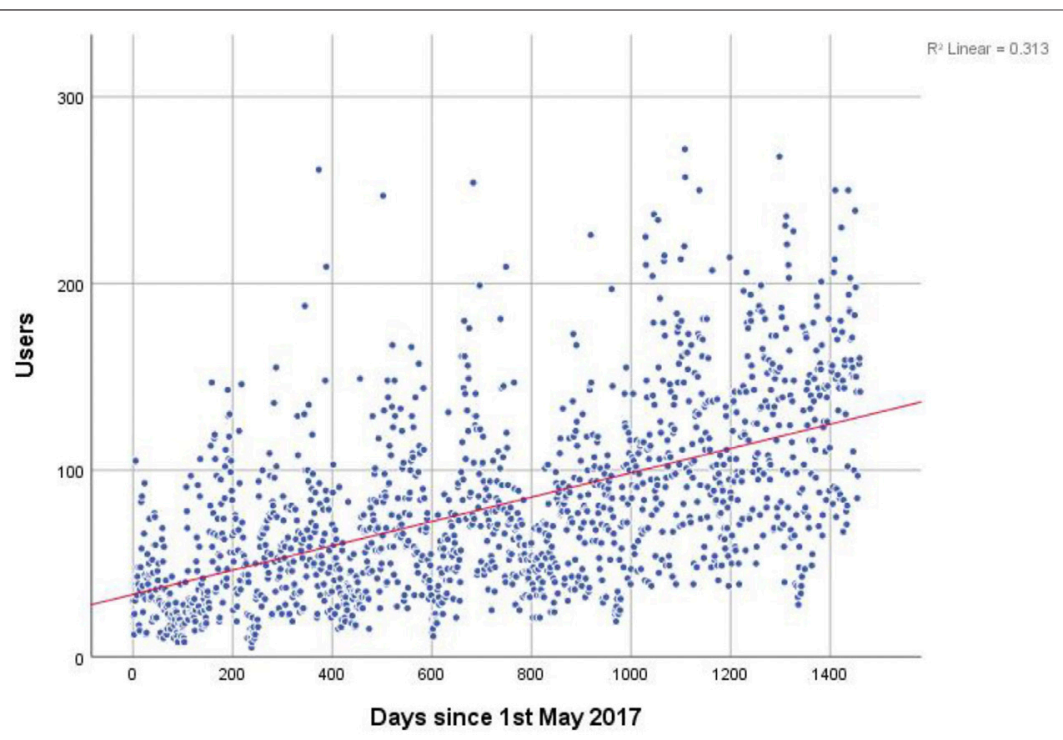

FIGURE 2 | A scatterplot showing the linear relationship between total users and number of days the CVI Scotland website has been active. 
upper middle income countries to appear on the list, at 26th and 27th respectively. No low income countries appear within the top 50 .

Table 5 which shows the number of users per million people in the local population of a country, indexed by the countries overall percentage of population (\%) with the actual number of users visiting the website by World Bank Income Group classification. It highlights that those countries with the fewest users, (South Sudan, Senegal, Sierra Leone, Mongolia and Haiti) are from low and lower middle income countries (yellow and orange colour). Whereas high income countries (purple) populate the top half. New Zealand has the most users of the website as a percentage of the overall population $(0.036 \%)$ but the United States has the most over all users of the website with 34,231 users being 0.01 percent of the population.

Table 6 shows the countries that have not accessed the website, with African nations predominating.

The finding that countries from Africa are not accessing the website as commonly as other nations is a striking contrast

TABLE 2 | Traffic Channel to CVI Scotland as a percentage and actual number of users.

\begin{tabular}{lccccc}
\hline $\begin{array}{l}\text { Traffic channel } \\
\text { \%/\# }\end{array}$ & Yr 1 & Yr 2 & Yr 3 & Yr 4 & $\begin{array}{c}\text { Average (\%)over } \\
\text { 4 Years }\end{array}$ \\
\hline Organic & $27 \%$ & $41 \%$ & $44 \%$ & $50 \%$ & 40.5 \\
& 3,075 & 6,750 & 9,502 & 16,191 & \\
\hline Direct & $40 \%$ & $31 \%$ & $33 \%$ & $30 \%$ & 33.5 \\
& 4,557 & 5,104 & 7,126 & 9,714 & \\
\hline Social & $25 \%$ & $21 \%$ & $17 \%$ & $14 \%$ & 19.3 \\
& 2,848 & 3,458 & 3,671 & 4,533 & 6.7 \\
\hline Referral & $8 \%$ & $7 \%$ & $6 \%$ & $6 \%$ & - \\
\hline Total users & 11,391 & 16,464 & 21,595 & 32,381 & \\
\hline
\end{tabular}

TABLE 3 | Age of users accessing CVI Scotland website as a percentage of total users with total user numbers.

\begin{tabular}{lcc}
\hline Age of user & Percent (\%) & $\begin{array}{c}\text { Number } \\
\text { of total users }\end{array}$ \\
\hline $18-24$ & 27.5 & 22,504 \\
$25-34$ & 33.5 & 27,413 \\
$35-44$ & 15.5 & 12,684 \\
$45-54$ & 12.5 & 10,228 \\
$55-64$ & 5.5 & 4,501 \\
$65+$ & 5.5 & 4,501
\end{tabular}

between the numbers of users from North America and Northern Europe compared to those from Africa.

\section{Device Used}

When we start to combine the GA data on the device used to access the website, and subcontinent analysis, as detailed in Table 7, we see divergence, with African countries using mobile phone devices rather than the desk top computers favoured in Europe and America. Tablets are the least likely device to be used to access the website no matter where in the world users are.

\section{Engagement}

The most frequently accessed pages (page views) are described in Table 8. This can be used as a de facto marker for the type of knowledge users are seeking, and provides an understanding of the information users most wish to know about. Searches within the website and searches from different websites and social media platforms, can give a range of different URLs for the same internet page. This accounts for why 12,614 pages have been recorded on Google Analytics, despite their being just over 600 pages on the CVI Scotland website. Several pages are link pages and have no content, including the home page, section pages, and the indexes. These have been excluded. The most frequently accessed content pages sought, concern visual acuity and the free reading tool called "LOOK." CVI Scotland developed "LOOK" with assistance from international experts, to help children with CVI to learn to read. Any text, up to 10,000 words in length, can be copied into a text box. Settings specific to the visual processing capabilities and needs of the individual user can be pre-set. These include how many words appear on screen at a time, from one to a single sentence, the text size, spacing, font, colour, background colour, gaps between words and speed. These settings, including the text and their place

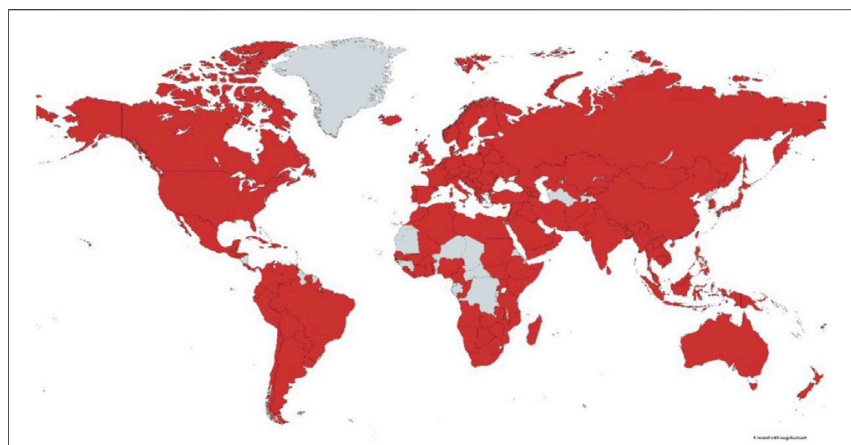

FIGURE 3 | A world map of the global reach of CVI Scotland.

TABLE 4 | Device used to access CVI Scotland as a percentage of total session by year - total sessions $141,, 051$ over the 4 years.

\begin{tabular}{|c|c|c|c|c|c|}
\hline $\begin{array}{l}\text { Devices \% } \\
\text { (by sessions) }\end{array}$ & Yr1 & Yr2 & Yr3 & Yr 4 & $\begin{array}{c}\text { Average over } \\
4 \text { Years }\end{array}$ \\
\hline Desktop/laptop & $51 \% 11,531$ & $50 \% 14,542$ & $55 \% 19,597$ & $60 \% 32,414$ & $55 \% 78,084$ \\
\hline Mobile & $36 \% 8,043$ & $40 \% 11,592$ & $37 \% 13,208$ & $36 \% 19,257$ & $37 \% 52,100$ \\
\hline Tablet & $13 \% 2,828$ & $10 \% 3,102$ & $8 \% 2,851$ & $4 \% 2086$ & $8 \% 10,867$ \\
\hline
\end{tabular}


TABLE 5 | Countries with most users, calculated as number of users per million people in the local population, percentage of population (\%) and actual number of users (\#). Countries classified by the World Bank Income Group classification.

\begin{tabular}{|c|c|c|c|}
\hline Country & $\begin{array}{l}\text { Users per million } \\
\text { of the population }\end{array}$ & $\%$ & $\#$ \\
\hline New Zealand & 368 & 0.036 & 1804 \\
\hline United Kingdom & 333 & 0.034 & 22,677 \\
\hline Ireland & 266 & 0.027 & 1,328 \\
\hline Australia & 150 & 0.015 & 3,858 \\
\hline Singapore & 123 & 0.013 & 725 \\
\hline United States of America & 103 & 0.01 & 34,231 \\
\hline Canada & 79 & 0.008 & 2,999 \\
\hline Sweden & 51 & 0.005 & 519 \\
\hline Hong Kong & 49 & 0.005 & 381 \\
\hline Norway & 45 & 0.005 & 244 \\
\hline Finland & 40 & 0.004 & 219 \\
\hline Denmark & 38 & 0.004 & 227 \\
\hline Netherlands & 37 & 0.004 & 640 \\
\hline Croatia & 30 & 0.003 & 118 \\
\hline Israel & 26 & 0.003 & 231 \\
\hline Taiwan & 25 & 0.002 & 588 \\
\hline UAE & 19 & 0.002 & 191 \\
\hline Belgium & 16 & 0.002 & 190 \\
\hline Switzerland & 12 & 0.001 & 102 \\
\hline Portugal & 10 & 0.001 & 107 \\
\hline Austria & 10 & 0.001 & 94 \\
\hline Greece & 10 & 0.001 & 103 \\
\hline Czechia & 9 & $>0.001$ & 94 \\
\hline Hungary & 9 & $>0.001$ & 82 \\
\hline France & 7 & $>0.001$ & 464 \\
\hline Germany & 7 & $>0.001$ & 550 \\
\hline Malaysia & 6 & $>0.001$ & 204 \\
\hline South Africa & 6 & $>0.001$ & 373 \\
\hline Spain & 5 & $>0.001$ & 222 \\
\hline Sri Lanka & 4 & $>0.001$ & 89 \\
\hline Poland & 4 & $>0.001$ & 153 \\
\hline Italy & 4 & $>0.001$ & 243 \\
\hline Saudi Arabia & 4 & $>0.001$ & 129 \\
\hline Turkey & 4 & $>0.001$ & 305 \\
\hline Peru & 3 & $>0.001$ & 111 \\
\hline South Korea & 2 & $>0.001$ & 119 \\
\hline Phillipines & 2 & $>0.001$ & 249 \\
\hline Argentina & 2 & $>0.001$ & 101 \\
\hline Egypt & 1 & $>0.001$ & 153 \\
\hline Thailand & 1 & $>0.001$ & 82 \\
\hline Japan & 1 & $>0.001$ & 140 \\
\hline Brazil & 1 & $>0.001$ & 214 \\
\hline India & 1 & $>0.001$ & 1,340 \\
\hline Russia & 1 & $>0.001$ & 135 \\
\hline Indonesia & 1 & $>0.001$ & 237 \\
\hline Bangladesh & 1 & $>0.001$ & 102 \\
\hline Pakistan & 1 & $>0.001$ & 124 \\
\hline Nigeria & 0 & $>0.001$ & 101 \\
\hline
\end{tabular}

TABLE 5 | (Continued) Countries with most users, calculated as number of users per million people in the local population, percentage of population (\%) and actual number of users (\#). Countries classified by the World Bank Income Group classification.

$\begin{array}{ll}\text { Country } & \begin{array}{l}\text { Users per million } \\ \text { of the population }\end{array}\end{array}$

\begin{tabular}{llll}
\hline China & 0 & $>0.001$ & 206
\end{tabular}

5 countries (of 170) with the fewest users

\begin{tabular}{llcc}
\hline South Sudan & 0 & $>0.001$ & 1 \\
Senegal & 0 & $>0.001$ & 1 \\
Sierra Leone & 0 & $>0.001$ & 1 \\
Mongolia & 0 & $>0.001$ & 1 \\
Haiti & 0 & $>0.001$ & 1
\end{tabular}

Low; Lower Middle; U Upper Middle; [ High.

in the text, which can be saved for next time, create a free-to-use e-reader specifically for people with CVI who are affected by visual crowding. As Table 8 shows, users most frequently appear to be seeking information about the different classifications of CVI, about visual acuity, neglect and visual inattention, visual fields, colour and contrast sensitivity, as well as behavioural manifestations of CVI such as CVI Meltdowns, and light gazing.

These content pages align with the most common search terms that have been identified through Google Analytics such as the term "Look Tool," "CVI Meltdown," "What is CVI" and "Understanding CVI". The most common search term typed into Google over the past 4 years has been the title of the website itself (CVI Scotland and its variants, i.e. cvi scotland, and CVI Scotland).

The duration of an average session reflects the interest of a user with respect to a particular page. GA can identify users as a "New User" (someone who has never visited the site before) or a "Returning Visitor" (where the JavaScript recognises through cookies that a user has visited the site before). Table 9 shows that the returning visitor spends almost twice as much time on the website as the new visitor.

The most popular "landing page" is the homepage, and of the people who land on this page, $40 \%$ go to the "What Is CVI?" section. The other section pages for resources, lessons and news are the next most frequently visited. Internationally, regardless of country, country income, volume of users, or device used, the trends of usage of the pages are remarkably similar. The users who come from social media, accounting for $19.3 \%$ of users, only view an average of 2.4 pages, whereas the referral users, representing $6.7 \%$ of users, viewed the most pages, with an average of 5.35 pages per session. There are five hundred different referral sources, but the majority are from vision, medical sources, education and academic organisations.

\section{DISCUSSION OF RESULTS}

To our knowledge this is the first study to examine the use of a website dedicated to CVI. As more and more professionals, 
TABLE 6 | Low and lower middle income countries with no users of the CVI Scotland website and their associated primary language of use.

\section{Africa}

Mauritania (Arabic)
The Gambia (English)
Guinea (French)
Guinea-Bissau (Portuguese)
Benin (French)
Niger (French)
French (Arabic)
Central African Republic (French/Sangho)
Equatorial Guinea (Spanish/French/Portuguese)
Gabon (French)
Congo (Rep) Brazzaville (French)
Rwanda (Kinyarwanda/English/French)
Burundi (French/English/Kirundi)
Western Sahara (Arabic/Spanish)

Asia

Tajikistan (Tajiki)

North Korea (Korean)

Central America

Nicaragua (Spanish)

patients and carers turn to the internet as a major source of health information, it is important that owners and developers understand how websites are being used and what sources of information are being accessed.

In this paper we have examined the use of the CVI Scotland website over a specified 4 year period and have demonstrated that the number of users accessing the website has significantly grown the longer it has been active. The website has gained traction amongst users worldwide, as increasing amounts of diverse salient content has been added. Previous users commonly return, spending more than twice as long accessing the pages as new users. This likely reflects the relevance and utility of the content to users. As awareness of CVI grows among professionals and the public, it can be expected that use of websites akin to CVI Scotland will consistently grow (Teoh, et al., 2021; Williams et al., 2021).

We have been able to determine where the users accessing the website come from, for the CVI Scotland website is being regularly accessed in 170 nations. Only a limited number of studies in high resource countries have reliably documented the prevalence of CVI. Yet the finding that the site is being used across so many countries, including many middle and low resource settings, indicates that the website is informing users and raising awareness of CVI in regions for which there is as yet, limited data on the numbers of people with the condition (Burton, et al., 2021). There is only a small number of countries where no users have been recorded. This likely reflects a lack of awareness of CVI in these regions, as well as English not being commonly used by the general public or professionals (Solebo et al., 2017; Keeffe, 2019). That information about CVI is being sought globally suggests a wider need to learn more about this disorder and how to cater for it especially as the website was developed to be dedicated to one single disorder and for one single purpose: understanding CVI. This appears to have been successful when measured by the evidence that the website is being accessed by users in a surprisingly wide range of countries.

Marton and Choo (2012), Manierre (2015) and Lee, (2021) all showed a gender difference in seeking health information behaviour with females more likely to seek health information on the internet than males. However, our results do not follow this digital gender divide, as we see slightly more males accessing the website than females although the split is nearly equal. This however may be a consequence of how GA collects data using the google account holder rather than the actual gender of the user at that time. However, meta-analysis studies such as Hallyburton and Evarts (2014) have shown that the difference between the genders for younger health information seekers is not as large as previous research suggests, although this narrowing of difference was explained by level of education. Our difference in gender finding is however interesting and although we cannot determine the exact cause of this difference through the limitation of this current analysis, it highlights a direction for future research.

Our study also adds to the body of literature that suggests there is a digital disparity of health information seekers in that certain groups of people are less like to access the internet for health information than others (Rains, 2007). Even being cautious about the limitation of how GA collects the age profile of users our data suggests that users over the age of 55 appear to be accessing CVI Scotland much less frequently than those between the ages of 18-34, representing over half of all users, is of concern, in that Ravenscroft and Wazny (2017) have shown that the median age of teachers of learners with visual impairment, is 50 years, with a median of only 10 years of experience. This important demographic concerning the delivery of sensory support to education, does not therefore appear to be accessing this website, even though it is highly relevant to them professionally. We can only speculate as to the reasons, but as Jacobs et al. (2017) show in their study of health information seeking among a United States population, older people are less confident using the internet as a source of information, preferring to use traditional print media. An alternative interpretation is that CVI Scotland is more focused on childhood visual impairment, than on adult visual impairment leading to those over the age of 55 years of age being less likely to use the resource.

Due to the limitations of GA data set use used for this project we were unable to investigate further avenues of reported digital discrepancies in terms of health seeking information by race, social economic status, and degree of education, however, as users to the website continue to increase this degree of analysis will form part of a later project.

Our results show less access to the website from users in Sub-Saharan Africa (SSA). This is likely to be due to a number of reasons such as lower awareness of the disorder compared to middle and higher resource settings combined with the focus of health care practitioners on more pressing acute general medical issues such as pneumonia, diarrhoea and malaria 
TABLE 7 | Difference of the type of device used to access CVI Scotland internationally, showing total usage percentage of each group of devices by region. Desktop includes laptop computers. Mobile includes all mobile/cell phone.

\begin{tabular}{clll} 
Type of device used & Primary $\%$ /\# & Secondary $\%$ /\# & Tertiary $\%$ /\#\# \\
\hline Americas & & & \\
\hline Northern America & Desktop & Mobile & Tablet \\
& $57 \% 21,175$ & $38 \% 14,063$ & $5 \% 1976$ \\
South America & Desktop & Mobile & Tablet \\
Central America & $51 \% 271$ & $47 \% 248$ & $2 \% 9$ \\
& Desktop & Mobile & Tablet \\
Caribbean & $52 \% 63$ & $44 \% 53$ & $4 \% 5$ \\
& Desktop & Mobile & Tablet \\
& $51 \% 38$ & $43 \% 32$ & $5 \% 4$
\end{tabular}

\section{Europe}

$\begin{array}{llll}\text { Northern Europe } & \text { Mobile } & \text { Desktop } & \text { Tablet } \\ & 46 \% 11,809 & 46 \% 11,601 & 8 \% 11,601 \\ \text { Western Europe } & \text { Desktop } & \text { Mobile } & \text { Tablet } \\ & 65 \% 1,331 & 30 \% 607 & 5 \% 116 \\ \text { Southern Europe } & \text { Desktop } & \text { Mobile } & \text { Tablet } \\ & 55 \% 533 & 39 \% 374 & 6 \% 58 \\ \text { Eastern Europe } & \text { Desktop } & \text { Mobile } & \text { Tablet } \\ & 60 \% 399 & 47 \% 245 & 3 \% 20\end{array}$

\section{Africa}

\begin{tabular}{|c|c|c|c|}
\hline Southern Africa & $\begin{array}{l}\text { Mobile } \\
55 \% 212\end{array}$ & $\begin{array}{l}\text { Desktop } \\
38 \% 145\end{array}$ & $\begin{array}{l}\text { Tablet } \\
7 \% 29\end{array}$ \\
\hline \multirow[t]{2}{*}{ Northern Africa } & Mobile & Desktop & Tablet \\
\hline & $54 \% 133$ & $45 \% 111$ & $1 \% 3$ \\
\hline \multirow[t]{2}{*}{ Western Africa } & Mobile & Desktop & Tablet \\
\hline & $61 \% 77$ & $35 \% 44$ & $4 \% 6$ \\
\hline \multirow[t]{2}{*}{ Eastern Africa } & Mobile & Desktop & Tablet \\
\hline & $56 \% 73$ & $43 \% 56$ & $1 \% 2$ \\
\hline \multirow[t]{2}{*}{ Middle Africa } & Mobile & Desktop & - \\
\hline & $73 \% 8$ & $27 \% 3$ & - \\
\hline \multicolumn{4}{|l|}{ Asia } \\
\hline \multirow[t]{2}{*}{ Southern Asia } & Mobile & Desktop & Tablet \\
\hline & $60 \% 1,058$ & $37 \% 662$ & $3 \% 43$ \\
\hline \multirow[t]{2}{*}{ Southeast Asia } & Mobile & Desktop & Tablet \\
\hline & $54 \% 856$ & $43 \% 680$ & $3 \% 45$ \\
\hline \multirow[t]{2}{*}{ Eastern Asia } & Desktop & Mobile & Tablet \\
\hline & $50 \% 717$ & $48 \% 689$ & $2 \% 29$ \\
\hline \multirow[t]{2}{*}{ Western Asia } & Desktop & Mobile & Tablet \\
\hline & $54 \% 589$ & $43 \% 468$ & $3 \% 38$ \\
\hline \multirow[t]{2}{*}{ Central Asia } & Desktop & Mobile & - \\
\hline & $55 \% 11$ & $45 \% 9$ & - \\
\hline \multicolumn{4}{|l|}{ Oceania } \\
\hline \multirow[t]{2}{*}{ Australasia } & Desktop & Mobile & Tablet \\
\hline & $55 \% 3,096$ & $35 \% 1978$ & $10 \% 593$ \\
\hline \multirow[t]{2}{*}{ Melanesia } & Mobile & Desktop & - \\
\hline & $60 \% 6$ & $40 \% 4$ & - \\
\hline \multirow[t]{2}{*}{ Polynesia } & Desktop & - & - \\
\hline & $100 \% 1$ & - & - \\
\hline
\end{tabular}

Rasanathan et al. (2014) as well as more attention being given to immediately treatable causes of child visual impairment such as cataract and uncorrected refractive error (Naidoo et al., 2020)

Another important reason for low use of the website in SSA would include barriers to internet access. Although mobile phone usage is common throughout Africa with its extensive $3 \mathrm{G}$ network, gaining access to internet data is expensive, while 'surfing' the internet is a luxury few can afford. The small handful of countries in SSA that have never accessed the CVI Scotland website are largely francophone and thus less likely to access an English language website. The users in SSA accessing the site do tend to use mobile devices rather than desktop computers or tablets. This should be taken into account in the design and layout of the website in the future, as efforts are made to increase traction in SSA, as CVI owing to perinatal brain injury due to prolonged labour is undoubtedly a significant issue in this region which needs to be addressed (Duke et al., 2019).

We have also understood the user's interaction through the website with surprising results. What we did not expect to find in the analysis was the number of page views of certain content areas. "LOOK," which is CVI Scotland's reading application, was one of the most frequently accessed web pages along with its supplementary pages, indicating a user led need for a greater resource to deal with the impact of CVI upon reading. This finding accords with the findings of Tsirka et al. (2020) who have ascertained through subjective feedback from parents, that strategies relating to reading (and navigation) were the most beneficial for the parents supporting their child with CVI, who reported that they wished they had learnt more about reading and intervention strategies earlier. If this finding is corroborated by further research, that indeed reading intervention and improvement strategies are what parents and professionals are seeking, then this has significant implications for future educational and habilitational approaches.

We also elicited a high level of engagement with topic areas such as visual acuity, visual fields (and lower visual field) and visual neglect. There may be a variety of reasons for this, for example, when a child visits a medical eye professional a general eye examination may take place in which an examination of basic visual functions including acuity and visual fields as well as refraction is carried out (Pehere and Jacob 2019; Lueck and Dutton, 2015; Corn and Erin 2010). This can be one of the first times that parents hear of these ophthalmic terms and are perhaps seeking further understanding of their meaning and significance (Rahi et al., 2003). While this is an inference, these data suggest that more information about these basic terms needs to be given, either at the clinic or through community/education work, to cater for this need (Paranjpe et al., 2016).

Similarly, the high usage of the search terms, "What is CVI" and "Understanding CVI" also suggests that users are seeking to gain an initial understanding of what CVI is, rather than going into more detail about the nature and impact of CVI, which is afforded by other less used pages of the website. This observation corresponds with the identity of the 'quick fact and skimmer' users' described by Pang et al. (2016). While we cannot determine whether these search terms were entered by children, parents or professionals, it is clear that such users (whosoever they are) have a need of such basic information. One possible solution to this issue is to provide an information leaflet about CVI, as well as details of the referral process to specialist support and provision, 
TABLE 8 | Content Pages and Number of Page Views accessed by users over a 4 year period.

\begin{tabular}{|c|c|}
\hline $\begin{array}{l}\text { Titles of content } \\
\text { pages accessed }\end{array}$ & $\begin{array}{c}\text { Total } \\
\text { page views } \\
\text { (4 Years) }\end{array}$ \\
\hline Visual Acuity & 9,536 \\
\hline LOOK Reading Tool & 9,492 \\
\hline COOL Colour Learning Tool & 5,367 \\
\hline CVI Classifications & 5,187 \\
\hline CVI Meltdowns & 4,963 \\
\hline CVI Scotland: About Us & 4,904 \\
\hline The Lists (For Profiling Individuals with CVI) & 4,357 \\
\hline Visual Neglect \& Visual Inattention & 4,245 \\
\hline LOOK (Reading Tool) introduction & 4,178 \\
\hline Simultanagnosia Spectrum & 4,053 \\
\hline Lower Visual Field Impairment & 3,734 \\
\hline First Read This (Introduction) & 3,540 \\
\hline Facial Recognition & 3,404 \\
\hline LOOK Reading Using Recognition & 3,316 \\
\hline Colour \& Contrast Sensitivity & 3,202 \\
\hline Light Gazing & 3,200 \\
\hline The Visual Field & 3,092 \\
\hline Introduction (to What Is CVI? Understand) & 3,073 \\
\hline $\begin{array}{l}\text { Three Rights (to learning, independence and social } \\
\text { confidence) }\end{array}$ & 2,842 \\
\hline (Understanding) Movement & 2,831 \\
\hline Colour & 2,712 \\
\hline Dorsal Stream Dysfunction (introduction) & 2,502 \\
\hline Cerebral Auditory Impairments & 2,335 \\
\hline The Visual Image (Introduction) & 2,305 \\
\hline Clutter & 2,226 \\
\hline The Image (the picture the brain creates) & 2,127 \\
\hline LOOK Newsletter & 2073 \\
\hline Looming (and Frights) & 1987 \\
\hline Lesson 1 Introduction & 1913 \\
\hline Simultanagnosia Spectrum Mixer Board & 1874 \\
\hline
\end{tabular}

at the time of diagnosis or suspected diagnosis. This approach has been shown to provide an effective channel for sharing information about CVI as it has been with other diseases (Heyns et al., 2021; Bester, et al., 2016; Rees et al., 2003).

We had expected to see more referrals to the CVI Scotland website from known social media platforms such as Facebook, Twitter, and Instagram, which are linked to google analytics. However we found that in contrast to the results of other similar research (Smailhodzic et al., 2016), that social media was one of the least frequent mechanism of referral to the website. Rather, users tended to directly type into a web browser the address of CVI Scotland. This would correspond with returning users either bookmarking the website, or remembering the address directly. It has been

TABLE 9 | Average Duration per session by type of user.

\begin{tabular}{lc}
\hline User type & Average session duration \\
\hline New Visitor & $2.51 \mathrm{~min}$ \\
Returning Visitor & $5.49 \mathrm{~min}$ \\
Average Duration & $4.07 \mathrm{~min}$
\end{tabular}

reported that 65 out of 180 countries have blocked or heavily restricted access to social media in the past 6 years and that Asian and African nations have done so the most Armstrong (2021), which may have contributed to this result. However, given the fact that the majority of users access the website in English, the blocking of social media may not have had a significant effect on overall access. These results highlight that before investing in social media for information websites like CVI Scotland, a more nuanced understanding of user access may be required.

As a result of this research several key developments will take place for the CVI Scotland website. The home page of the website has already been redesigned as a result of this analysis which showed every month thousands of new users were visiting the website for the first time, and most landing on the home page. The detrimental effects of user frustration when trying to access health information were highlighted by (Finney Rutton et al., 2019); Fareed et al. (2021), with evidence suggesting this frustration can lead to a greater divide between those gaining the benefits of health information, and those who do not. To aid easy navigation the homepage is much simpler, with multiple options to help the new user find what they are looking for, including a short video tour of the website. The most used pages are being reviewed and updated. CVI Scotland had previously only used GA to track users and countries. CVI Scotland realised the benefits for future analysis, of more detailed information about the race, lifestyle and education of their users, compared to their country and what they are accessing on the website, and as such additional research will be developed to collect this data.

Future plans include accessibility options, focusing on affordability for populations, particularly in SSA where mobile phones are used but data is very expensive. By creating a datalight option, ensuring affordability of access through mobile data connectivity, it is hoped to increase more awareness of CVI in these regions. Other plans may include non-digital formats, including leaflets and guides for free distribution.

\section{LIMITATIONS}

There are some key limitations to using Google Analytics as a vehicle to determine user interest in CVI. The first is that Google does not track everything that happens on the CVI Scotland website, so the numbers given need to be treated as approximations. With increasing concern over the past decade, in how Google specifically, and the Internet in general, uses and tracks personal data, awareness of how to opt out of Google Analytics has grown considerably. Users may therefore be blocking cookies or switching off JavaScript on their web browser rendering Google Analytics unable track the behaviour of visitors to CVI Scotland, which would cause under reporting of user data. Finally, there is a chance that some of the data will have been over reported, in that Google Analytics cannot guarantee that it has excluded all "bot" activity such as search engine web crawler/spiders that are used to index the context of CVI Scotland for search engine results, despite the setting to remove known bots and spiders being activated.

With the average user time on the website being only a few minutes, reflecting 'quick fact seeking strategy' it is important to 
ensure that information is packaged in small 'bitesize' pages. The course of Lessons teaching CVI were designed with this in mind, and each comprises a short video tutorial, typically being 3 minutes long, with a short complementary website page providing further explanation.

CVI Scotland continues to grow, attracting three to four thousand users a month of whom around a quarter are returning users. With over six hundred pages to choose from, the facility to simply navigate the website is extremely important, particularly from the home page, where the majority of new users initially "land".

\section{CONCLUSION}

Through the analysis of GA our specific research question has been answered. We have found that the CVI Scotland website is an ongoing, dynamic and responsive globally visited resource, created through international collaboration among the authors. However, it is clear from this study of user access, that there is a need for more information and resources on visual impairment generally and CVI specifically. Public awareness of CVI does appear to be growing, and this growth is reflected in the usage of the CVI Scotland website over the 4 year period it has been in operation as an open freely accessible website. Geographical variation in location of users suggests that a focus of attracting users in lower economic countries and in particular SSA should be a future focus and to ensure the site is accessible on mobile phones using minimum data. Educational websites are often the first port of call for people trying to understand a given diagnosis, and this is no different for CVI.

\section{REFERENCES}

Ahluwalia, S., Murray, E., Stevenson, F., Kerr, C., and Burns, J. (2010). 'A Heartbeat Moment': Qualitative Study of GP Views of Patients Bringing Health Information from the Internet to a Consultation. Br. J. Gen. Pract. 60 (571), 88-94. doi:10.3399/bjgp10x483120

AlGhamdi, K. M., and Moussa, N. A. (2012). Internet Use by the Public to Search for Health-Related Information. Int. J. Med. Inform. 81 (6), 363-373. doi:10.1016/j.ijmedinf.2011.12.004

Arcaro, M. J., Thaler, L., Quinlan, D. J., Monaco, S., Khan, S., Valyear, K. F., et al. (2019). Psychophysical and Neuroimaging Responses to Moving Stimuli in a Patient with the Riddoch Phenomenon Due to Bilateral Visual Cortex Lesions. Neuropsychologia 128, 150-165. doi:10.1016/j.neuropsychologia.2018.05.008

Armstrong, M. (2021). Where Social media Is Suppressed. Available at: https:// www.statista.com/chart/23804/countries-blocking-social-media/.

Bester, N., Di Vito-Smith, M., McGarry, T., Riffkin, M., Kaehler, S., Pilot, R., et al. (2016). The Effectiveness of an Educational Brochure as a Risk Minimization Activity to Communicate Important Rare Adverse Events to Health-Care Professionals. Adv. Ther. 33 (2), 167-177. doi:10.1007/ s12325-016-0284-y

Brewer, N. T., Haugtvedt, C. P., Machleit, K. M., and Yalch, R. (2005). “The Impact of Internet Use on Health Cognitions and Behavior," in Online Consumer Psychology: Understanding and Influencing Consumer Behavior in the Virtual World (Mahwah, NJ: Lawrence Erlbaum).

Burton, M. J., Ramke, J., Marques, A. P., Bourne, R. R. A., Congdon, N., Jones, I., et al. (2021). The Lancet Global Health Commission on Global Eye Health: Vision beyond 2020. Lancet Glob. Health 9 (4), e489-e551. doi:10.1016/S2214109X(20)30488-5

\section{DATA AVAILABILITY STATEMENT}

The raw data supporting the conclusions of this article will be made available by the authors, without undue reservation.

\section{ETHICS STATEMENT}

Ethical review and approval was not required for the study on human participants in accordance with the local legislation and institutional requirements. Written informed consent for participation was not required for this study in accordance with the national legislation and the institutional requirements.

\section{AUTHOR CONTRIBUTIONS}

JR and HT devised the study with support from AB. Analysis was conducted by HT with support from JR. Themes and structure of the analysis were all agreed by all authors. The manuscript was drafted by JR, with significant contributions from HT and AB. All authors have agreed this final submitted version.

\section{ACKNOWLEDGMENTS}

The Authors would like to acknowledge the help and support from Professor Gordon Dutton, who internally reviewed this manuscript and acted as a critical friend during the writing process. We would also like to express our gratitude to Peroosh for full access to the website they designed.

Clark, D. J., Nicholas, D., and Jamali, H. R. (2014). Evaluating Information Seeking and Use in the Changing Virtual World: the Emerging Role of Google Analytics. Learn. Pub. 27 (3), 185-194. doi:10.1087/20140304

Corn, A. L., and Erin, J. N. (2010). Foundations of Low Vision: Clinical and Functional Perspectives. American Foundation for the Blind.

Crutzen, R., Roosjen, J. L., and Poelman, J. (2013). Using Google Analytics as a Process Evaluation Method for Internet-Delivered Interventions: an Example on Sexual Health. Health Promot. Int. 28 (1), 36-42. doi:10.1093/heapro/ das008

Duke, R., Eyong, K., Burton, K., MacLeod, D., Dutton, G. N., Gilbert, C., et al. (2019). The Effect of Visual Support Strategies on the Quality of Life of Children with Cerebral Palsy and Cerebral Visual Impairment/perceptual Visual Dysfunction in Nigeria: Study Protocol for a Randomized Controlled Trial. Trials 20 (1), 417-512. doi:10.1186/s13063-019-3527-9

Dutton, G. N. (2021). Cerebral Visual Impairment in Children: the Importance of Classification. Dev. Med. Child. Neurol. 63 (3), 245. doi:10.1111/dmcn.14684

Fareed, N., Swoboda, C. M., Jonnalagadda, P., Walker, D. M., and Huerta, T. R. (2021). Differences between Races in Health Information Seeking and Trust over Time: Evidence from a Cross-Sectional, Pooled Analyses of HINTS Data. Am. J. Health Promot. 35 (1), 84-92. doi:10.1177/ 0890117120934609

Finney Rutten, L. J., Blake, K. D., Greenberg-Worisek, A. J., Allen, S. V., Moser, R. P., and Hesse, B. W. (2019). Online Health Information Seeking Among US Adults: Measuring Progress toward a Healthy People 2020 Objective. Public Health Rep. 134 (6), 617-625. doi:10.1177/0033354919874074

Gardiner, R. (2008). The Transition from 'informed Patient' Care to 'patient Informed' Care. Stud. Health Technol. Inform. 137 (5), 241-256.

Gorrie, F., Goodall, K., Rush, R., and Ravenscroft, J. (2019). Towards Population Screening for Cerebral Visual Impairment: Validity of the Five Questions and 
the CVI Questionnaire. PloS one 14 (3), e0214290. doi:10.1371/ journal.pone. 0214290

Hallyburton, A., and Evarts, L. A. (2014). Gender and Online Health Information Seeking: A Five Survey Meta-Analysis. J. Consumer Health Internet 18 (2), 128-142. doi:10.1080/15398285.2014.902268

Head, H., Rivers, W. H. R., Sherren, J., Holmes, G., Thompson, T., and Riddoch, G. (1920). "Sensory Disturbances Associated with Certain Lesions of the Optic Thalamus," in Studies in Neurology, in Two Vols. Editors H. Head, W. H. R. Rivers, J. Sherren, G. Holmes, T. Thompson, and G. Riddoch (Collaborators (Hodder and Stoughton: Oxford University Press), Vol. 2, 551-569. doi:10.1037/14233-012

Heyns, J., Van Huyssteen, M., and Bheekie, A. (2021). The Effectiveness of Using Text and Pictograms on Oral Rehydration, Dry-Mixture Sachet Labels. Afr. J. Prim. Health Care Fam. Med. 13 (1), 1-11. doi:10.4102/phcfm.v13i1.2646

Hodge, N., and Runswick-Cole, K. (2008). Problematising Parent-Professional Partnerships in Education. Disabil. Soc. 23 (6), 637-647. doi:10.1080/ 09687590802328543

Holmes, G. (1918a). Disturbances of Vision by Cerebral Lesions. Br. J. Ophthalmol. 2 (7), 353-384. doi:10.1136/bjo.2.7.353

Holmes, G. (1918c). Disturbances of Vision by Cerebral Lesions. Br. J. Ophthalmol. 2 (7), 353-384. doi:10.1136/bjo.2.7.353

Holmes, G. (1918b). Disturbances of Visual Orientation. Br. J. Ophthalmol. 2 (9), 449-468. doi:10.1136/bjo.2.9.449

Jackel, B. (2019). A Survey of Parents of Children with Cortical or Cerebral Visual Impairment: 2018 Follow-Up. Semin. Pediatr. Neurol. 31, 3-4. doi:10.1016/ j.spen.2019.05.002

Jackel, B., Wilson, M., and Hartmann, E. (2010). A Survey of Parents of Children with Cortical or Cerebral Visual Impairment. J. Vis. Impairment Blindness 104 (10), 613-623. doi:10.1177/0145482x1010401007

Jacobs, W., Amuta, A. O., and Jeon, K. C. (2017). Health Information Seeking in the Digital Age: An Analysis of Health Information Seeking Behavior Among US Adults. Cogent Soc. Sci. 3 (1), 1302785. doi:10.1080/ 23311886.2017.1302785

Keeffe, J. (2019). "Global Data on Vision Loss," in The Routledge Handbook of Visual Impairment: Social and Cultural Research. Editor J. Ravenscroft (New York, NY: Routledge). doi:10.4324/9781315111353-2

Kirk, M., Morgan, R., Tonkin, E., McDonald, K., and Skirton, H. (2012). An Objective Approach to Evaluating an Internet-Delivered Genetics Education Resource Developed for Nurses: Using Google Analytics to Monitor Global Visitor Engagement. J. Res. Nurs. 17 (6), 557-579. doi:10.1177/1744987112458669

Kong, L., Fry, M., Al-Samarraie, M., Gilbert, C., and Steinkuller, P. G. (2012). An Update on Progress and the Changing Epidemiology of Causes of Childhood Blindness Worldwide. J. Am. Assoc. Pediatr. Ophthalmol. Strabismus 16 (6), 501-507. doi:10.1016/j.jaapos.2012.09.004

Lee, H. Y., Jin, S. W., Henning-Smith, C., Lee, J., and Lee, J. (2021). Role of Health Literacy in Health-Related Information-Seeking Behavior Online: Cross-Sectional Study. J. Med. Internet Res. 23 (1), e14088. doi:10.2196/ 14088

Lueck, A. H., and Dutton, G. (2015). Vision and the Brain: Understanding Cerebral Visual Impairment in Children. New York: AFB press.

Manierre, M. J. (2015). Gaps in Knowledge: Tracking and Explaining Gender Differences in Health Information Seeking. Soc. Sci. Med. 128, 151-158. doi:10.1016/j.socscimed.2015.01.028

Martín, M. B. C., Santos-Lozano, A., Martín-Hernández, J., López-Miguel, A., Maldonado, M., Baladrón, C., et al. (2016). Cerebral versus Ocular Visual Impairment: the Impact on Developmental Neuroplasticity. Front. Psychol. 7, 1958. doi:10.3389/fpsyg.2016.01958

Martini, M., and Bragazzi, N. L. (2021). Googling for Neurological Disorders: From Seeking Health-Related Information to Patient Empowerment, Advocacy, and Open, Public Self-Disclosure in the Neurology 2.0 Era. J. Med. Internet Res. 23 (3), e13999. doi:10.2196/13999

Marton, C., and Wei Choo, C. (2012). A Review of Theoretical Models of Health Information Seeking on the Web. J. Documentation 68 (3), 330-352. doi: $10.1108 / 00220411211225575$

McDowell, N. (2021). A Review of the Literature to Inform the Development of a Practice Framework for Supporting Children with Cerebral Visual Impairment (CVI). Int. J. Inclusive Education, 1-21. doi:10.1080/ 13603116.2020.1867381
McDowell, N. (2020). Power Is Knowledge: Empowering Parents of Children with Cerebral Visual Impairment. Disabil. Soc. 36, 1-22. doi:10.1080/ 09687599.2020 .1751586

Naidoo, K., Kempen, J. H., Gichuhi, S., Braithwaite, T., Casson, R. J., Cicinelli, M. V., et al. (2020). Prevalence and Causes of Vision Loss in Sub-saharan Africa in 2015: Magnitude, Temporal Trends and Projections. Br. J. Ophthalmol. 104 (12), 1658-1668. doi:10.1136/bjophthalmol-2019-315217

Pang, P. C.-I., Chang, S., Verspoor, K., and Pearce, J. (2016). Designing Health Websites Based on Users' Web-Based Information-Seeking Behaviors: A Mixed-Method Observational Study. J. Med. Internet Res. 18 (6), e145. doi:10.2196/jmir.5661

Paranjpe, R., Mushtaq, I., Thakre, A., Sharma, A., Dutta, D., and Iqbal, B. (2016). Awareness of Childhood Blindness in Parents Attending Paediatrics Ophthalmology Outpatient Department. Med. J. Dr. DY Patil Univ. 9 (4), 451. doi:10.4103/0975-2870.192144

Pehere, N., and Jacob, N. (2019). Understanding Low Functioning Cerebral Visual Impairment: An Indian Context. Indian J. Ophthalmol. 67 (10), 1536 doi:10.4103/ijo.ijo_2089_18

Rafferty, K. A., and Sullivan, S. L. (2017). "You Know the Medicine, I Know My Kid": How Parents Advocate for Their Children Living with Complex Chronic Conditions. Health Commun. 32 (9), 1151-1160. doi:10.1080/10410236.2016.1214221

Rahi, J. S., Manaras, I., and Barr, K. (2003). Information Sources and Their Use by Parents of Children with Ophthalmic Disorders. Invest. Ophthalmol. Vis. Sci. 44 (6), 2457-2460. doi:10.1167/iovs.02-1184

Rains, S. A. (2007). Perceptions of Traditional Information Sources and Use of the World Wide Web to Seek Health Information: Findings from the Health Information National Trends Survey. J. Health Commun. 12, 667-680. doi:10.1080/10810730701619992

Rasanathan, K., Muñiz, M., Bakshi, S., Kumar, M., Solano, A., Kariuki, W., et al. (2014). Community Case Management of Childhood Illness in Sub-saharan Africa - Findings from a Cross-Sectional Survey on Policy and Implementation. J. Glob. Health 4 (2), 020401. doi:10.7189/jogh.04.020401

Ravenscroft, J., and Wazny, K. (20172021). The Qualification of Teachers of Pupils with Visual Impairment, or Pupils with Hearing Impairment or Pupils with MultiSensory Impairment (Vision and Hearing Impairment). Available at: http://www. ssc.education.ed.ac.uk/research/sg_teachers_sensory_impairment.pdf.

Rees, C. E., Ford, J. E., and Sheard, C. E. (2003). Patient Information Leaflets for Prostate Cancer: Which Leaflets Should Healthcare Professionals Recommend?. Patient Education Couns. 49 (3), 263-272. doi:10.1016/s07383991(02)00188-x

Riddoch, G. (1917). On the Relative Perceptions of Movement and a Stationary Object in Certain Visual Disturbances Due to Occipital Injuries. Proc. R. Soc. Med. 10 (Neurol_Sect), 13-34. doi:10.1177/003591571701000802

Russ, H., Giveon, S. M., Catarivas, M. G., and Yaphe, J. (2011). The Effect of the Internet on the Patient-Doctor Relationship from the Patient's Perspective: a Survey from Primary Care. Isr. Med. Assoc. J. 13 (4), 220-224.

Sakki, H. E. A., Dale, N. J., Sargent, J., Perez-Roche, T., and Bowman, R. (2018). Is There Consensus in Defining Childhood Cerebral Visual Impairment? A Systematic Review of Terminology and Definitions. Br. J. Ophthalmol. 102 (4), 424-432. doi:10.1136/bjophthalmol-2017-310694

Smailhodzic, E., Hooijsma, W., Boonstra, A., and Langley, D. J. (2016). Social media Use in Healthcare: A Systematic Review of Effects on Patients and on Their Relationship with Healthcare Professionals. BMC Health Serv. Res. 16 (1), 442-514. doi:10.1186/s12913-016-1691-0

Solebo, A. L., Teoh, L., and Rahi, J. (2017). Epidemiology of Blindness in Children. Arch. Dis. Child. 102 (9), 853-857. doi:10.1136/archdischild-2016-310532

Soul, Janet., and Matsuba, Carey. (2010). "Causes of Damage to the Visual Brain," in Visual Impairment in Children Due to Damage to the Brain. Editors G. N. Dutton and M. Bax (London: Mac Keith Press), 20-40.

Tan, S. S.-L., and Goonawardene, N. (2017). Internet Health Information Seeking and the Patient-Physician Relationship: a Systematic Review. J. Med. Internet Res. 19 (1), e9. doi:10.2196/jmir.5729

Teoh, L. J., Solebo, A. L., Rahi, J. S., Morton, C., Allen, L., McPhee, D., et al. (2021). Visual Impairment, Severe Visual Impairment, and Blindness in Children in Britain (BCVIS2): a National Observational Study. Lancet Child. Adolesc. Health 5 (3), 190-200.

Tsirka, A., Liasis, A., Kuczynski, A., Vargha-Khadem, F., Kukadia, R., Dutton, G., et al. (2020). Clinical Use of the Insight Inventory in Cerebral Visual 
Impairment and the Effectiveness of Tailored Habilitational Strategies. Dev. Med. Child. Neurol. 62 (11), 1324-1330. doi:10.1111/dmcn.14650

Kraan, C. F., Drossaert, C. H., Taal, E., Shaw, B. R., Seydel, E. R., and van de Laar, M. A. (2008). Empowering Processes and Outcomes of Participation in Online Support Groups for Patients with Breast Cancer, Arthritis, or Fibromyalgia. Qual. Health Res. 18 (3), 405-417. doi:10.1177/ 1049732307313429

Warde, F., Papadakos, J., Papadakos, T., Rodin, D., Salhia, M., and Giuliani, M. (2018). Plain Language Communication as a Priority Competency for Medical Professionals in a Globalized World. Can. Med. Ed. J. 9 (2), e52-59. doi: $10.36834 / \mathrm{cmej} .36848$

Wicklund, K., and Ramos, K. (2009). Plain Language: Effective Communication in the Health Care Setting. J. Hosp. Librarianship 9 (2), 177-185. doi:10.1080/ 15323260902812740

Williams, C., Pease, A., Warnes, P., Harrison, S., Pilon, F., Hyvarinen, L., et al. (2021). Cerebral Visual Impairment-related Vision Problems in Primary School Children: a Cross-sectional Survey. Dev. Med. Child. Neurol. 63 (6), 683-689. doi:10.1111/dmcn.14819

Young, S., Shakespeare-Finch, J., and Obst, P. (2020). Raising a Child with a Disability: a One-Year Qualitative Investigation of Parent Distress and Personal Growth. Disabil. Soc. 35 (4), 629-653. doi:10.1080/ 09687599.2019 .1649637

Conflict of Interest: The authors declare that the research was conducted in the absence of any commercial or financial relationships that could be construed as a potential conflict of interest.

Publisher's Note: All claims expressed in this article are solely those of the authors and do not necessarily represent those of their affiliated organizations, or those of the publisher, the editors and the reviewers. Any product that may be evaluated in this article, or claim that may be made by its manufacturer, is not guaranteed or endorsed by the publisher.

Copyright (C) 2021 Ravenscroft, St Clair Tracy and Blaikie. This is an open-access article distributed under the terms of the Creative Commons Attribution License (CC $B Y)$. The use, distribution or reproduction in other forums is permitted, provided the original author(s) and the copyright owner(s) are credited and that the original publication in this journal is cited, in accordance with accepted academic practice. No use, distribution or reproduction is permitted which does not comply with these terms. 